\title{
Do vazio mental ao vazio corporal: um olhar psicanalítico sobre as comunidades virtuais pró-anorexia ${ }^{1}$
}

\author{
Melina Vianna Fava \\ Universidade Federal de São Carlos, São Carlos-SP, Brasil \\ Rodrigo Sanches Peres ${ }^{2}$ \\ Universidade Federal de Uberlândia, Uberlândia-MG, Brasil
}

\begin{abstract}
Resumo: Ambientes virtuais "pró-anorexia", ou seja, voltados à promoção e perpetuação do transtorno em questão, têm se proliferado na internet pelo mundo todo. O presente artigo tem como objetivo empreender uma leitura psicanalítica de comunidades virtuais desta natureza. Trata-se de um estudo documental, no qual se privilegiou a abordagem qualitativa e o enfoque naturalístico. As descrições de dez comunidades virtuais "pró-anorexia" brasileiras foram submetidas a análises descritivas e exploratórias. Tais análises evidenciam que a negação da natureza psicopatológica do transtorno e a recusa da própria feminilidade fomentam a conduta anoréxica. Observou-se também uma tendência à personificação da anorexia nervosa, o que pode ser indicador de uma importante fragilidade narcísica. Dessa forma, consideramos oportuno alinhar a anorexia nervosa ao conceito nosográfico de vazio mental, condição patológica potencializada pela sociedade atual. Portanto, entendemos que, na anorexia nervosa, os ditames repressores da cultura promovem uma espécie de transposição do vazio mental ao vazio corporal.
\end{abstract}

Palavras-chave: anorexia nervosa, psicanálise, internet (rede de computador).

\section{From mental emptiness to body emptiness: a psychoanalytical view on pro-anorexia virtual communities}

\begin{abstract}
Pro-anorexia" virtual environments, which focus on the promotion and perpetuation of this disorder, have proliferated on the internet around the world. This paper presents a psychoanalytic view on virtual communities of this nature. This is a documentary study with a qualitative and naturalistic approach. The descriptions of ten Brazilian "pro-anorexia" virtual communities were submitted to descriptive and exploratory analyses. These analyses show that the denial of the psychopathological nature of the disorder and the refusal of one's own femininity promote the anorexic behavior. A tendency to personify anorexia nervosa was observed, which indicates an important narcissistic fragility. Thus, we consider appropriate to align anorexia nervosa to the nosological concept of mental emptiness, a pathological condition potentiated by the current society. Therefore, we believe that from the perspective of anorexia nervosa, the dictates of cultural repression promote a kind of transposition from mental emptiness to body emptiness.
\end{abstract}

Keywords: anorexia nervosa, psychoanalysis, internet.

\section{Del vacío mental al vacío corporal: una visión psicoanalítica sobre las comunidades virtuales pro-anorexia}

\begin{abstract}
Resumen: Los ambientes virtuales "pro-anorexia", o sea, volteados a la promoción y perpetuación del trastorno en cuestión, se han proliferado en la internet por todo el mundo. El presente estudio tiene como finalidad emprender una lectura psicoanalítica de las comunidades virtuales de esta naturaleza. Se trata de un estudio documental, en el cual se privilegió la aproximación cualitativa y el enfoque naturalista. Las descripciones de diez comunidades virtuales "pro-anorexia" brasileñas fueron sometidas a análisis descriptivas y exploratorias. Esas análisis evidencian que la negación de la naturaleza psicopatológica del trastorno y la repulsa de la propia feminidad fomentan la conducta anoréxica. Se ha observado también una tendencia a la personificación de la anorexia nerviosa, en la cual representa el indicador de una importante fragilidad narcisista. De esta forma, consideramos oportuno alinear la anorexia nerviosa al concepto nosológico del vacío mental, una condición patológica potencializada por la actual sociedad. Por lo tanto, entendemos que, en la anorexia nerviosa, los dictámenes represores de la cultura promueven una especie de transposición del vacío mental al vacío corporal.
\end{abstract}

Palabras clave: anorexia nerviosa, psicoanálisis, internet.

A anorexia nervosa é um transtorno alimentar significativamente mais frequente em mulheres, em cuja etiologia

\footnotetext{
${ }^{1}$ Este texto foi revisado seguindo o Acordo Ortográfico da Língua Portuguesa (1990), em vigor a partir de $1^{\circ}$ de janeiro de 2009.

${ }^{2}$ Endereço para correspondência:

Rodrigo Sanches Peres. Universidade Federal de Uberlândia. Instituto de Psicologia. Avenida Pará, 1720/ Bloco 2C, campus Umuarama. CEP 38.405-320. Uberlândia-MG, Brasil. E-mail: rodrigosanchesperes@yahoo.com.br
}

fatores biológicos, psicológicos, sociais e culturais podem, interagindo entre si, atuar como predisponentes, precipitantes e mantenedores (Morgan, Vecchiatti, \& Negrão, 2002). Segundo os sistemas de classificação dos transtornos mentais vigentes, os aspectos psicopatológicos centrais desse transtorno são o medo mórbido de engordar e o controle obsessivo do peso corporal (American Psychiatric Association, 2002; Organização Mundial da Saúde, 1993). Ambos levam ao emprego de dietas extremamente restritivas, à utilização 
exacerbada de métodos purgativos ou à prática excessiva de exercícios físicos.

Claudino e Borges (2002) salientam que outra característica psicopatológica importante na anorexia nervosa é a severa perturbação no modo de vivenciar o peso corporal. Motivada pela autoavaliação obsessivamente baseada na forma física, essa perturbação fomenta a busca desenfreada da magreza (Peres \& Santos, 2006). Logo, alguns autores propõem que a característica em questão deve ser considerada um critério operacional para o diagnóstico. Entretanto, é preciso reconhecer que não raro pacientes portadores de outros transtornos mentais e até mesmo indivíduos saudáveis apresentam uma percepção inapropriada de sua forma física.

Obviamente os sistemas de classificação dos transtornos mentais têm desempenhado um papel decisivo para a sistematização do conhecimento em psicopatologia. Todavia, Pereira (1996) alerta que esses, supostamente em nome de um "compromisso prático", são constituídos a partir de pressupostos operacionais que promovem uma redução dos fenômenos psicopatológicos a seus aspectos empiricamente acessíveis. A psicanálise, em contrapartida, privilegia a perspectiva da dimensão subjetiva do funcionamento psíquico, de modo que pode contribuir, como disciplina científica, para a ampliação do horizonte conceitual e metodológico da pesquisa em psicopatologia.

Kelner (2004) inclusive defende que a referência à psicanálise é imprescindível para a compreensão dos transtornos alimentares por possibilitar um delineamento da singularidade do paciente em suas facetas mais profundas. Porém, entre os inúmeros estudos dedicados à anorexia nervosa nos últimos anos, é possível notar o predomínio de abordagens biológicas, cognitivas ou comportamentais, o que, como bem enfatiza Fernandes (2006), tem levado a uma utilização da psicanálise nesse contexto incompatível com toda a fecundidade teórica que lhe é característica. Por compartilharmos dessas idéias, discutiremos a seguir algumas passagens da obra freudiana que subsidiam uma delimitação da psicopatologia da anorexia nervosa em termos psicanalíticos.

\section{Anorexia nervosa: breve percurso pela obra freudiana}

Conforme Fernandes (2006), Freud não dedicou nenhum de seus textos especificamente à anorexia nervosa. Entretanto, considerações de grande relevância acerca desse transtorno podem ser localizadas em sua obra. A primeira delas remonta à publicação do historial clínico de uma paciente anônima que apresentou sintomas de anorexia nervosa nos meses subsequentes ao nascimento de cada um de seus três filhos. Freud (1893/1996) observou em tal paciente uma tendência primária à depressão, condição que ele, na época, atribuía um papel decisivo na organização neurótica. Contudo, o historial clínico referido também possibilita articular a anorexia nervosa a problemáticas relativas à feminilidade $\mathrm{e}$ à maternidade.
Quando da publicação do historial clínico de Emmy von N., paciente em cujo quadro clínico a anorexia nervosa ocupava um lugar de destaque, Freud postulou que a função alimentar pode ser comprometida pela ocorrência de eventos traumáticos. Emmy von N. relatou que perdeu completamente o apetite após presenciar a morte de seu marido sem nada poder fazer para socorrê-lo por estar acamada em função do resguardo puerperal. Não obstante, Freud afirmou ainda que "ela comia tão pouco por não gostar do sabor, e não podia apreciar o sabor porque o ato de comer, desde os primeiros tempos, se vinculara a lembranças de repulsa cuja soma de afeto jamais diminuíra em qualquer grau" (1895/1996a, p. 118).

Tal afirmação se sustenta levando-se em conta que, durante as sessões de hipnose conduzidas por Freud, Emmy von N. mencionou que, quando criança, era forçada por sua mãe a comer sua refeição por completo. Tendo em vista que demorava a fazê-lo, os alimentos esfriavam e passavam a lhe causar repugnância. Ademais, a paciente em questão admitiu que, em certa época, tinha receio de ser contaminada por seus irmãos - os quais haviam sido acometidos por varíola e tuberculose - ao dividir a mesa com os mesmos. Freud (1895/1996a) concluiu que a repulsa de Emmy pela comida foi reativada em função de um evento traumático porque havia sido recalcada quando da situação original, permanecendo assim até irromper devido à ação do inconsciente.

Freud (1895/1996b) retoma a aproximação entre a anorexia nervosa e a depressão ao associar, em um texto teórico, a perda de apetite à perda da libido. A anorexia nervosa poderia, então, ser considerada uma espécie de melancolia que acomete indivíduos, sobretudo do sexo feminino, cuja sexualidade não se desenvolveu plenamente. Quando da publicação do historial clínico de Dora, adolescente judia virgem, essa tese é embasada no estabelecimento de uma relação entre o surgimento de seu comportamento alimentar patológico e seu envolvimento com um amigo de seu pai. Para Freud (1905/1996), os sintomas de Dora decorriam basicamente da incapacidade da paciente manejar as emergências pulsionais típicas da juventude potencializadas pela natureza edípica da situação por ela vivenciada.

No historial clínico do "homem dos lobos", Freud (1918/1996) atribui a eclosão do quadro neurótico desenvolvido pelo paciente na idade adulta a problemas ocorridos em sua infância, particularmente aqueles referentes ao fato de o mesmo ter observado uma relação sexual de seus pais. Os graves sintomas fóbicos, obsessivos e paranoides do paciente, de acordo com o raciocínio freudiano, tiveram como ponto de partida sua perda de apetite, a qual, por sua vez, foi precipitada pelos conflitos associados à cena primária. Afinal, o "homem dos lobos" se encontrava, na ocasião, atravessando a fase oral, permanecendo, portanto, fixado à equação alimentação-sexualidade, característica dessa etapa da organização da libido.

Apresentar um exame detalhado das contribuições freudianas para o delineamento da psicopatologia da anorexia nervosa foge ao escopo do presente estudo. Entretanto, 
tendo em vista o que precede, pode-se constatar que Freud procurava compreendê-la mediante a utilização do modelo etiológico da histeria, ressaltando os desdobramentos do recalcamento sobre o erotismo oral no que tange à organização da sexualidade e o papel de eventos traumáticos como precipitantes dos sintomas. Além disso, não deixava de registrar a dimensão melancólica da anorexia nervosa. Tais proposições forneceram os elementos nos quais autores contemporâneos, representantes de diversas vertentes psicanalíticas, se apoiaram na busca de uma compreensão mais detalhada do transtorno em questão em suas distintas manifestações na atualidade.

\section{Anorexia nervosa: entre o real e o virtual}

Nos últimos anos um fenômeno intrigante tem ocorrido na internet: a proliferação mundial de ambientes virtuais "pró-anorexia", tais como web sites, comunidades, blogs e chats, dentre outros. Geralmente mantidos e frequentados por jovens do sexo feminino, os ambientes virtuais dessa natureza visam, de modo geral, a promover e perpetuar o transtorno em questão a partir da divulgação de dietas restritivas e métodos purgativos que, se efetivamente empregados, oferecem risco importante à vida. Diante do exposto, conclui-se que, como defendem Hamilton e Bowers (2006), a internet se destaca como valiosa fonte de dados para pesquisadores que se dedicam ao estudo do funcionamento psíquico de pacientes anoréxicas, uma vez que essas constituem uma população de difícil acesso.

Por esse motivo, diversas publicações internacionais recentes têm recorrido a tal fonte de dados. Em uma dessas publicações, Norris, Boydell, Pinhas e Katzman (2006) descreveram o conteúdo de web sites "pró-anorexia" em língua inglesa. A veiculação de estratégias capazes de promover perda de peso perigosamente rápida, assim como a divulgação de meios favoráveis ao acobertamento de seus sintomas associados, é, segundo a constatação dos autores, frequente na maioria dos web sites pesquisados. Além disso, fotos de celebridades esquálidas são apresentadas como "inspiração", relacionando o ideal de beleza centrado na magreza à ascensão financeira, ao sucesso profissional e à aceitação social.

Brotsky e Gilles (2007) examinaram as crenças referentes ao transtorno e ao tratamento veiculadas em diferentes comunidades virtuais "pró-anorexia" em língua inglesa. Tal estudo apontou que muitas frequentadoras das comunidades virtuais pesquisadas entendem que a anorexia nervosa "escolhe" suas vítimas, o que evidencia a crença de que elas não têm controle sobre a própria vida. Essa crença enseja uma atitude conformista, a qual, de acordo com depoimentos postados nas comunidades virtuais pesquisadas, tende a dificultar a adesão ao tratamento. Constatou-se ainda que as comunidades virtuais criam uma espécie de "miragem social", promovendo o sentimento de apoio do qual suas mantenedoras e frequentadoras se queixam de não experimentar nos relacionamentos interpessoais.
Empreender uma análise dos depoimentos "pró-anorexia" postados em um chat em língua inglesa foi o objetivo do estudo de Gavin, Rodhan e Poyer (2008). Os resultados reportados ilustram que o surgimento das alterações fisiológicas que acompanham a perda de peso excessiva - lanugo e alopecia, dentre outras - são celebradas pelas frequentadoras do chat pesquisado como um sinal de sucesso. Isso ocorre porque as mesmas consideram a anorexia nervosa um "estilo de vida", e não um transtorno. De acordo com os autores, contudo, observa-se nas entrelinhas da maioria dos depoimentos um sentimento subjacente de anormalidade. Embora o discurso autodepreciativo seja bem aceito no chat pesquisado, expressões desse sentimento são desestimuladas a partir de depoimentos que defendem a naturalização da busca desenfreada da magreza.

Diversos outros estudos sobre ambientes virtuais "próanorexia" publicados recentemente em periódicos internacionais poderiam ser citados. Em contrapartida, nenhuma pesquisa nacional - conforme uma revisão bibliográfica empreendida previamente em bases de dados online - foi publicada em periódicos brasileiros indexados abordando especificamente o assunto em questão. Considerou-se pertinente, assim, oferecer uma contribuição inicial para o preenchimento dessa lacuna com o desenvolvimento do presente estudo, cujo objetivo é empreender uma leitura psicanalítica das descrições de comunidades virtuais "pró-anorexia". Tal opção teórica se justifica tendo em vista que, como mencionado anteriormente, a psicanálise, embora possa subsidiar a compreensão de importantes aspectos psicopatológicos do referido transtorno, tem sido pouca aproveitada para tanto em pesquisas recentes.

\section{Método}

\section{Coleta de dados}

A coleta de dados do presente estudo foi realizada junto a dez comunidades virtuais "pró-anorexia" brasileiras, as quais foram localizadas a partir de consultas realizadas mediante o emprego da ferramenta de busca da maior rede social disponível no país. O descritor adotado para tanto foi a expressão "pro-ana", tipicamente utilizada na internet sem acento agudo - para designar posicionamento favorável ao emprego de dietas restritivas e métodos purgativos como recursos básicos na busca desenfreada da magreza. Mais especificamente, foram selecionadas, entre as dezenas de comunidades virtuais dessa natureza localizadas a partir das consultas realizadas, aquelas: (a) cujas descrições foram consideradas, após uma análise preliminar, representativas do movimento "pró-anorexia"; (b) que apresentavam conteúdo aberto a não membros, ou seja, veiculavam material de domínio público.

É preciso esclarecer ainda que trabalhamos com uma amostragem por saturação. Trata-se de uma ferramenta frequente em pesquisas qualitativas, a partir da qual, conforme 
Fontanella, Ricas e Turato (2008), a interrupção da coleta de dados é definida quando da identificação, por parte do pesquisador, de certa redundância de informações. Ou seja: consideramos que ampliar o número de comunidades virtuais "pró-anorexia" selecionadas para os fins do presente estudo pouco ou nada acrescentaria frente ao objetivo proposto, uma vez que notamos repetições que sinalizavam a existência de diversos elementos comuns em suas descrições.

Diante do exposto, conclui-se que privilegiamos o desenho metodológico da pesquisa documental, pois a descrição das comunidades virtuais, por prescindir de conhecimentos especializados para sua produção e refletir o modo como as pessoas se expressam, pode, considerando-se a categorização de Bauer, Gaskell e Allum (2002), ser classificado sob a rubrica de documentos informais. Além disso, deve-se enfatizar que se trata de material de domínio público, sem qualquer restrição de acesso. Logo, a coleta de dados do presente estudo se alinha àquelas situações para as quais as diretrizes éticas vigentes sobre pesquisas envolvendo seres humanos autorizam a dispensa de consentimento.

\section{Análise dos dados}

A abordagem qualitativa foi adotada no presente estudo, de modo que os dados coletados foram submetidos a análises majoritariamente descritivas e exploratórias buscando-se a interpretação da significação simbólica dos mesmos a partir da interlocução com autores que, sobretudo em nosso meio, têm se dedicado à proposição de elementos psicanalíticos para a compreensão da anorexia nervosa em suas diversas nuances. Vale lembrar que a abordagem qualitativa, trabalhando com valores, crenças, representações, hábitos, atitudes e opiniões, se mostra especialmente proveitosa "para aprofundar a complexidade de fenômenos, fatos e processos particulares e específicos de grupos mais ou menos delimitados em extensão e capazes de serem abrangidos intensamente" (Minayo \& Sanches, 1993, p. 247). Atesta-se, portanto, sua pertinência frente ao objetivo proposto.

Vale destacar ainda que o presente estudo privilegiou o enfoque da pesquisa naturalística, uma vez que, conforme Selltiz, Wrightsman e Cook (1987), as investigações científicas desse tipo não têm como propósito principal testar hipóteses, mas sim descrever um fenômeno tal como ocorre e nas circunstâncias que o geram. A propósito, Mulveen e Hepworth (2006) salientam que o conteúdo de comunidades virtuais goza de caráter essencialmente naturalístico em função de sua espontaneidade. Cumpre assinalar, por fim, que, frente ao objetivo proposto, foram contempladas apenas as descrições das comunidades virtuais selecionadas. Essa opção justifica-se tendo em vista que as descrições, propostas pelas mantenedoras das comunidades virtuais, sintetizam a ideologia com a qual se identificam a maioria de suas frequentadoras.

\section{Resultados}

Cada uma das dez comunidades virtuais selecionadas para os fins do presente estudo terá sua descrição apresentada no corpo do texto. Devemos esclarecer que optamos por substituir o nome dessas comunidades virtuais por números que representam a ordem em que foram localizadas, descartando-se, obviamente, aquelas que não atendiam aos critérios de inclusão estabelecidos. Ocorre que parte do nome de algumas comunidades virtuais era composto por nomes próprios, possivelmente de suas mantenedoras. É preciso mencionar ainda que, em alguns casos, julgamos mais oportuno apresentar apenas excertos - considerados representativos das descrições devido à extensão das mesmas. Em todos os casos mantivemos o conteúdo de modo literal, com erros de grafia, acentuação, abreviações e gírias.

A descrição das comunidades virtuais 1, 4, 5 e 6 exemplifica claramente a negação da natureza psicopatológica do transtorno em questão. Tal fenômeno, observado também, ainda que de modo menos explícito, na descrição das demais comunidades virtuais selecionadas para os fins do presente estudo, poderia ser entendido, a princípio, como o reflexo da grave perturbação da imagem corporal típica de pacientes anoréxicas. Mas, para Fernandes (2006), essa perturbação, por atingir, muitas vezes, proporções verdadeiramente delirantes, encontra-se relacionada, em última instância, à dificuldade na discriminação das fronteiras entre o sujeito e o objeto, a qual, por sua vez, sugere clivagem entre o ego e o corpo. Seguem as descrições: "Sou pro anna. Adoro não comer nada, pois sei q no final o resutado é maravilhoso, ser pro anna não é doença, é uma opção um estilo de vida" (Comunidade 5).

E aqui está o porquê de não assumir o seu transtorno: quando vc se sentar num restaurante pra jantar as pessoas da sua mesa vão se divertir reparando o tdo q vc come e não come e te pentelhando. Quem sabe assim não percebem q estão ingerindo $5555 \mathrm{cal}$, entupindo as veias de gordura e ninguem perceba os 3 alcolatras na mesa bolinando a garçonete. (...) Resumindo, pense 300x antes de revelar ao mundo (falar pra mãe = falar pro mundo, ja viu mãe guardar segredo qdo a filha pede? vcs viram as costas $e$ elas catam o telefone pra chorar as pitangas com a tia/amiga/massagista, se bobear vão contar até pro cabelereiro e pra manicure) que vc é ana (...). Se fizerem vai ser foda pq o mundo é hipócrita, injusto e cheio de gente invejosa, que não consegue emagrecer e que vc fique muito gorda. (Comunidade 1)

Fome passa; gordura não. Se vc comer vai estragar o esforço q fez ontem. Comer é vício. Comer é para 
fracos. Vc controla a sua mente. Olha essas gorduras, tudo o q ve come aumenta elas. (...) As Anas estão com vc;e elas não estão comendo... E estão ficando mais magras q vc. Beba um copo de água. Comer não é normal... (...). Não é pq todo mundo come vc tem q comer $T b$. Não pense q está fazendo algo de errado, vc não está. (Comunidade 4)

\section{Eu quero caminhar sem deixar pegadas}

20. A beleza está nos ossos

50. A comida é nojenta

58. Ana será minha amiga

96. Eu não vivo uma doença, eu vivo um estilo de vida.

98. Doença não é querer emagrecer, doença é ser gorda.

99. motivos pelo qual vivo uma vida pró ana! Ana: Um estilo de vida! (Comunidade 6)

Parece plausível cogitar que, diante dessa clivagem, os conteúdos pulsionais tendem a se perder dos conteúdos cognitivos, o que inviabiliza um contato protetor com as angústias mais básicas. Logo, o ego deixa de exercer sua função adaptativa e o aparelho psíquico passa a falsear a realidade, promovendo o que Fernandes (2006) chama de hipocondria da imagem. Possivelmente, por isso, conforme se observa na descrição das comunidades virtuais 7,8 e 10, a anorexia nervosa é entendida como a consequência de uma escolha. Entretanto, trata-se de uma escolha fundada na recusa do desejo. E, como reforça a autora em pauta, a psicanálise demonstra de maneira eloquente que a recusa incide justamente sobre o desejo que, devido à sua intensidade e ambiguidade, não pode ser controlado mediante o emprego de outro expediente. Seguem as descrições: "Sou uma Ana e tenho muito orgulho disso (...). Minha lei é ser magra" (Comunidade 7); "Cansei de ser aquela gorda que não pode colocar um biquine ou um tope que as banhas caem (...). Eool e Ana agora, somos melhores amigas as melhores mesmo, ela vai mudar minha vida com ela eu vo até o fim!" (Comunidade 8).

Sou Ana nunca vou deixar de ser pq isso e um estilo d vida n uma "doença" como os otros que nao entendem julgam. Sou Ana porque... (...) Porque estou cansada deste circulo vicioso de comida. (...) Porque comida é igual a Crack. (...) Porque eu vou provar que posso conseguir. (...) Porque eu sempre quis isso. (...) Porque eu posso fazer isso! (Comunidade 10)

Mas qual seria esse desejo? Entendemos que tal indagação poderia ser respondida basicamente da seguinte forma: trata-se do desejo pelo outro. Afinal, Fucks (2003) salienta que a conduta anoréxica, revelando a assunção de um ideal ascético, tem como meta anular o corpo pulsional e sexuado. Tal meta é correlativa de uma marcante recusa da própria feminilidade, pois sugere que a condição de mulher, por ser comumente associada pelas pacientes à passividade e à submissão, é vivenciada como algo intolerável. Parece razoável considerar um bom exemplo dessa associação a referência, na descrição da comunidade virtual 1, à figura da garçonete que se sujeita aos gestos libidinosos dos alcoólatras no restaurante.

Referendando essa linha de raciocínio, vale lembrar que a perda de apetite na anorexia nervosa era associada, na obra freudiana, à perda da libido. Contudo, como já mencionamos, a fixação na fase oral e a ocorrência de eventos traumáticos eram apontadas como precipitantes tanto de uma quanto da outra. A efetiva compreensão da recusa do desejo pelo outro demanda, a nosso ver, uma mudança de ênfase na abordagem da problemática anoréxica. Para Fucks (2003), essa problemática resulta da batalha entre mãe e filha, em cuja origem pode ser identificada a busca de autonomia e diferenciação.

Trata-se de uma batalha deslocada para outros territórios, na medida em que a adoção de dietas extremamente restritivas pode ser entendida como tentativa de implementar um controle onipotente sobre o próprio organismo. Ocorre que, segundo Goulart (2003), o corpo anoréxico testemunha a introjeção da figura materna como objeto possessivo e opressor, fenômeno que, por sua vez, é favorecido pela passividade da figura paterna. É nesse sentido que Miranda (2004) defende que a complexidade da relação mãe-filha na anorexia nervosa se deve essencialmente a uma falha na internalização do triângulo edípico e faz da recusa do desejo pelo outro uma medida extrema de reasseguramento da integridade narcísica.

Já a descrição das comunidades virtuais $2,3,4,6,7$, 8,9 e 10 atesta uma espécie de personificação da anorexia nervosa. Esse fenômeno pode ser entendido como um desdobramento da tendência à afirmação de um saber particular sobre a própria condição psicopatológica. Portanto, em contraste com o que faziam as histéricas do período vitoriano, as anoréxicas dos dias de hoje não buscam o reconhecimento do discurso médico como forma de legitimação. Nesse sentido, Fucks (2003) afirma que muitas delas apresentam um funcionamento psíquico que se alinha mais às modalidades paranoicas do que às modalidades neuróticas. Seguem as descrições: "Dez mandamentos da Ana: (...) 2. guardar pelo menos 5 reais da mesada/salário para os laxantes/diuréticos/ inibidores, (...) 4. nunca mais gastar seu dinheiro com comida, (...) 6. rejeitar o máximo de refeições, (...) 9. mentir quando necessário" (Comunidade 3); "Mandamentos da ana: 1 - Olhe no espelho e diga a vc mesmo que está gorda. 2 - (...) Você nunca estará magra o suficiente. 3 - Olhe imagens de mulheres belas e magras diariamente. 4 - Não pense ou coma comida. Comida lhe faz engordar" (Comunidade 9).

Meu nome é Anorexia, mas você pode me chamar de Ana. Nós podemos nos tornar grandes amigas. Diziam q você era tão madura, inteligente, que você 
tinha tanto potencial. E eu pergunto, aonde tudo isso foi parar? Absolutamente em lugar algum! Você perde tempo falando com seus amigos! Logo, esses atos não serão mais permitidos. Seus amigos não são verdadeiros. Quando inseguramente você perguntou a eles: - Estou gorda? - E eles te disseram: - Não, claro que não! - Você sabia que eles estavam mentindo! Apenas eu digo a verdade! E sem falar nos seus pais! Irei te contar um segredo agora: bem no fundo, eles estão desapontados com você. Porque você se transformou em uma gorda, lerda, e sem merecimento de nada! (Comunidade 2)

A típica desconfiança das pacientes em relação a familiares e amigos por não as apoiarem em sua busca desenfreada pela magreza - patente na descrição das comunidades virtuais 1, 2, 3 e 9 - também pode ser considerada uma evidência da vertente paranoica do transtorno. Parece razoável propor ainda que a personificação da anorexia nervosa representa, em última instância, o indicador de uma importante fragilidade narcísica, visto que atesta a insustentabilidade da autossuficiência que, conforme Kelner (2004), muitas anoréxicas se esforçam para demonstrar. A propósito: se a suposta autossuficiência visa à anulação da necessidade do objeto, entendemos que poderia ela, então, ser considerada correlativa da anulação da necessidade do alimento buscada por meio da prática de dietas extremamente restritivas.

A descrição das referidas comunidades virtuais, portanto, é representativa dos antagonismos e das incoerências que, para Miranda (2004), ocupam lugar central na psicopatologia da anorexia nervosa e fazem dela uma espécie de protótipo da configuração ilógica do inconsciente. A autora esclarece que essa configuração se torna evidente partindo-se do princípio de que o aparelho psíquico de muitas pacientes - sobretudo adolescentes como a maioria das mantenedoras e frequentadoras das comunidades virtuais "pró-anorexia" selecionadas para os fins do presente estudo - é incapaz de codificar as mensagens corporais de maneira apropriada.

Tal incapacidade remete aos primórdios da vida mental. Afinal, como bem observaram Clemente e Peres (2010), a progressiva dessomatização do aparelho psíquico tem início na primeira infância, com a interpretação, por parte da figura materna, da comunicação primitiva dos estados afetivos de seu bebê. Nos casos em que essa tarefa não é desempenhada adequadamente, os sinais pré-verbais que o bebê emite permanecem distantes de qualquer código linguístico, de modo que suas experiências, sejam elas corporais ou emocionais, não serão devidamente simbolizadas. Sendo assim, o mesmo não terá condições de diferenciar adequadamente seu corpo do mundo externo. De acordo com Goulart (2003), na anorexia nervosa isso comumente ocorre devido à intrusividade da figura materna.

\section{Discussão}

De modo geral, os resultados ora reportados complementam aqueles obtidos pelas pesquisas internacionais já citadas que utilizaram a internet como fonte de dados. Afinal, a veiculação de métodos para a promoção e perpetuação do transtorno, observada por Norris e cols. (2006) em web sites "pró-anorexia" em língua inglesa, pode ser considerada uma das diversas formas de expressão de uma relação peculiar com a verdade, determinada por tentativas de apropriação subjetiva da própria condição psicopatológica. Nesse sentido, equivale à personificação da anorexia nervosa explicitada na descrição das comunidades virtuais $2,3,4,6,7,8,9$ e 10 .

Brotsky e Gilles (2007) verificaram que muitas frequentadoras de comunidades virtuais "pró-anorexia" em língua inglesa demonstram conformismo em relação ao surgimento e ao desenvolvimento do transtorno. Essa atitude claramente se encontra associada a uma acentuada fragilidade narcísica. Não ocorreram, na descrição das comunidades virtuais selecionadas para os fins do presente estudo, indicadores tão gritantes dessa característica. Entretanto, constatamos que a fragilidade narcísica típica de pacientes anoréxicas pode também se revelar em negativo, sobretudo, como revela a descrição das comunidades virtuais 1, 2, 3 e 9, a partir das afirmações insustentáveis de autossuficiência potencializadas pela desconfiança em relação a amigos e familiares.

Já Gavin e cols. (2008) observaram que, de acordo com os depoimentos postados em um chat "pró-anorexia" de língua inglesa, comumente o transtorno não é entendido como tal por suas frequentadoras, mas sim como um "estilo de vida". Esse mesmo fenômeno, como já mencionamos, foi encontrado nas descrições das comunidades virtuais 7, 8 e 10. A nosso ver, trata-se de um indicador da inviabilidade de qualquer contato com angústias arcaicas. Logo, pode-se delinear uma condição correlativa à clivagem entre o ego e o corpo, equivalente àquela que antecede a inclusão, na primeira infância, de conflitos primitivos em cadeias de significação.

O presente estudo oferece também contribuições originais para o aprofundamento do conhecimento atualmente disponível sobre o assunto em pauta, na medida em que, em contraste com as pesquisas internacionais referidas, fundamenta-se na psicanálise. Assim, contempla aspectos mais subjetivos da anorexia nervosa, os quais se situam para além das manifestações sintomáticas diretamente observáveis consideradas pelos sistemas de classificação dos transtornos mentais e, em maior ou menor grau, encontram-se presentes em outros ambientes virtuais "pró-anorexia", quer sejam eles nacionais ou internacionais. Dessa maneira, as análises apresentadas fornecem subsídios potencialmente proveitosos para generalizações naturalísticas, instrumentalizando, consequentemente, outros autores a explorar facetas do transtorno que não foram abordadas nesta oportunidade. 
Como já mencionado, Fucks (2003) e Fernandes (2006), respectivamente, destacam a dimensão paranoica e hipocondríaca da anorexia nervosa. Além disso, Kelner (2004) e Miranda (2004) salientam que a recusa do desejo que perpassa as diferentes manifestações do transtorno em questão lhe confere um traço de perversão. Endossamos essas proposições tendo em vista que, nas descrições das comunidades virtuais selecionadas para os fins do presente estudo, encontramos elementos que revelam a pertinência de ampliar a concepção freudiana sobre a anorexia nervosa, especialmente no que se refere à utilização do modelo etiológico da histeria como principal recurso para se compreender os fatores predisponentes do transtorno.

Devemos acrescentar ainda que, para Fucks (2003), a adoção de dietas extremamente restritivas tem como finalidade básica minimizar, mediante a indução da sensação de vazio corporal, a emergência de angústias de intrusão. Por outro lado, sugere também a busca de uma autonomia que, visando à anulação da necessidade do objeto, se mostra impraticável. Conforme Goulart (2003), essa busca se afigura, em última instância, como uma defesa contra um vazio de outra natureza, instituído pela malograda dessomatização do aparelho psíquico na primeira infância e perpetuado por seu principal desdobramento nas etapas subsequentes do ciclo vital: a utilização maciça do aparelho sensório-motor como via de escoamento das tensões.

Portanto, podemos propor que o modelo etiológico das neuroses atuais, tal como originalmente proposto por Freud (1895/1996c), fornece insumos potencialmente proveitosos para a compreensão dos fatores predisponentes da anorexia nervosa. Afinal, segundo esse modelo, os sintomas físicos da neurose de angústia, da neurastenia e da hipocondria - quadros clínicos que constituem as neuroses atuais - não resultam da conversão, mas, sim, de processos que prescindem de mediação psíquica (Peres, 2006). É nesse sentido que Ferraz (2007) sugere que, nas neuroses atuais, sintomas físicos predominam devido à superação dos limites do representável e à consequente instituição de um funcionamento mental regulado por esquemas filogenéticos, aquém, portanto, da colonização libidinal do corpo.

Diante do exposto, consideramos oportuno alinhar a anorexia nervosa ao conceito nosográfico de vazio mental. Tal condição psicopatológica resulta, de acordo com Lisondo (2004), da fragilidade narcisista na coesão das identificações estruturantes. Como bem observou Lutemberg (2003), o vazio mental, enquanto conceito nosográfico, se diferencia do vazio mental enquanto condição circunstancial: o primeiro corresponde a uma carência estrutural e específica de representações inconscientes e pré-conscientes tipicamente inferidas por suas derivações defensivas secundárias, ao passo que o segundo pode ser referido diretamente a partir da associação livre como um fenômeno dinâmico circunscrito ao plano das emoções.

O conceito nosográfico de vazio mental é agregador, dado que, para Lisondo (2004), pode subsidiar a compreensão dos aspectos psicopatológicos centrais de diversos quadros clínicos, dentre os quais, além da anorexia nervosa, se destacam as adicções e somatizações Afinal, em cada um desses quadros se observa, com certas especificidades, uma eterna busca de completude motivada e potencializada pela falta de experiências reais. Conforme Brusset (1996), o vazio corporal, para a anoréxica, é vivenciado como a única garantia da própria integridade justamente porque tais experiências reais são interpretadas como ameaças em potencial. Ocorre que, como já mencionamos, o ego deixa de exercer sua função adaptativa e as fronteiras entre o sujeito e o objeto passam se confundir.

A sociedade contemporânea cria uma conjuntura potencialmente favorável ao vazio mental ao enaltecer o consumo, a sedução e o imediatismo. É por essa razão que Lisondo (2004) destaca que a profundidade das vivências emocionais é pulverizada por jogos de aparência determinados por modismos que levam o ser humano a caminhar na contramão das exigências para a estruturação do psiquismo. Portanto, estamos de acordo com Miranda (2004) quando afirma que, na anorexia nervosa, os ditames repressores da cultura, na medida em que atualmente incidem sobre o comportamento alimentar, e não mais sobre o comportamento sexual, como ocorria no período vitoriano, promovem uma espécie de transposição do vazio mental ao vazio corporal.

As mantenedoras e frequentadoras das comunidades virtuais pesquisadas aparentemente procuram preencher esse vazio mental e, ao mesmo tempo, atender às exigências de uma cultura que estabelece a perfeição como imperativo. $\mathrm{Ou}$ seja: a anorexia nervosa pode ser considerada uma manifestação do mal-estar da mulher na civilização atual, a qual se encontra associada a conflitos irredutíveis ao comportamento alimentar propriamente dito. Essa linha de raciocínio foi sintetizada com propriedade por Fernandes (2006) ao afirmar que "se o corpo das histéricas deu voz à problemática feminina do século XIX, parece ser o corpo em negativo das anoréxicas que vem, em nossos dias, ocupando esse lugar" (p. 110).

\section{Considerações finais}

O presente estudo, ao empreender uma leitura psicanalítica sobre comunidades virtuais "pró-anorexia" brasileiras, aborda um assunto ainda pouco explorado na literatura científica nacional. Tendo em vista sua complexidade, conclui-se que novas pesquisas se fazem necessárias. A propósito: entendemos que investigar a interação via internet das frequentadoras dos ambientes virtuais dessa natureza - quer sejam web sites, comunidades, blogs ou chats - pode complementar os resultados ora reportados. Assim, outros aspectos da psicopatologia da anorexia nervosa, somando-se àqueles colocados em relevo no presente estudo a partir do exame das descrições das comunidades virtuais selecionadas, possivelmente serão melhor compreendidos. 


\section{Referências}

American Psychiatric Association. (2002). Manual diagnóstico e estatístico de transtornos mentais (4a ed. rev., C. Dornelles, Trad.). Porto Alegre: ArtMed.

Bauer, M. W., Gaskell, G., \& Allum, N. C. (2002). Qualidade, quantidade e interesses do conhecimento: Evitando confusões. In M. W. Bauer \& G. Gaskell (Orgs.), Pesquisa qualitativa com texto, imagem e som: Um manual prático (pp. 17-36, P. A. Guareschi, Trad.). Petrópolis, RJ: Vozes.

Brotsky, S. R., \& Giles, D. (2007). Inside the pro-ana community: A covert online participant observation. Eating Disorders, 15(2), 93-109.

Brusset, B. (1996). Anorexia mental y toxicomanía (C. B. Moguillansky, Trad.). Psicoanálisis, 18(2), 189-221.

Claudino, A. M., \& Borges, M. B. F. (2002). Critérios diagnósticos para os transtornos alimentares: Conceitos em evolução. Revista Brasileira de Psiquiatria, 24(3), $7-12$.

Clemente, J. P. L., \& Peres, R. S. (2010). Funcionamento psíquico e manejo clínico de pacientes somáticos: Reflexões a partir da noção de desafetação. Psicologia Clínica, 22(2), 57-69.

Fernandes, M. H. (2006). Transtornos alimentares: Anorexia e bulimia. São Paulo: Casa do Psicólogo.

Ferraz, F. C. (2007). A tortuosa trajetória do corpo na psicanálise. Revista Brasileira de Psicanálise, 41(4), 66-76.

Freud, S. (1996). Um caso de cura pela hipnose. In J. Salomão (Org.), Edição standard brasileira das obras psicológicas completas de Sigmund Freud (J. L. Meurer, Trad., Vol. 1, pp. 159-170). Rio de Janeiro: Imago. (Originalmente publicado em 1893)

Freud, S. (1996a). Caso 2 - Sra. Emmy Von N., 40 anos, da Livônia. In J. Salomão (Org.), Edição standard brasileira das obras psicológicas completas de Sigmund Freud (C. M. Oiticica \& V. Ribeiro, Trad., Vol. 2, pp. 82-133). Rio de Janeiro: Imago. (Originalmente publicado em 1895)

Freud, S. (1996b). Rascunho G: Melancolia. In J. Salomão (Org.), Edição standard brasileira das obras psicológicas completas de Sigmund Freud (J. L. Meurer, Trad., Vol. 1, pp. 246-253). Rio de Janeiro: Imago. (Originalmente publicado em 1895)

Freud, S. (1996c). Sobre os fundamentos para destacar da neurastenia uma síndrome específica denominada neurose de angústia. In J. Salomão (Org.), Edição standard brasileira das obras psicológicas completas de Sigmund Freud (M. Salomão, Trad., Vol. 3, pp. 93-115). Rio de Janeiro: Imago. (Originalmente publicado em 1895)

Freud, S. (1996). Fragmento da análise de um caso de histeria. In J. Salomão (Org.), Edição standard brasileira das obras psicológicas completas de Sigmund Freud (V. Ribeiro, Trad., Vol. 7, pp. 15-108). Rio de Janeiro: Imago. (Originalmente publicado em 1905)
Freud, S. (1996). História de uma neurose infantil. In J. Salomão (Org.), Edição standard brasileira das obras psicológicas completas de Sigmund Freud (E. A. M. Souza, Trad., Vol. 17, pp. 15-129). Rio de Janeiro: Imago. (Originalmente publicado em 1918)

Fontanella, B. J. B., Ricas, J., \& Turato, E. R. (2008). Amostragem por saturação em pesquisas qualitativas em saúde: Contribuições teóricas. Cadernos de Saúde Pública, 24(1), 17-27.

Fucks, M.P. (2003). O mínimo é o máximo: Uma aproximação da anorexia. In R. M. Volich, F. C. Ferraz, \& W. Ranña (Orgs.), Psicossoma III: Interfaces da psicossomática (pp. 147-158). São Paulo: Casa do Psicólogo.

Gavin, J., Rodhan, K., \& Poyer, H. (2008). The presentation of pro-anorexia in online groups interaction. Qualitative Health Research, 18(3), 325-333.

Goulart, M. T. A. (2003). Anorexia nervosa: Uma leitura psicanalítica. Dissertação de mestrado não publicada, Pontifícia Universidade Católica do Rio de Janeiro, Rio de Janeiro.

Hamilton, R. J., \& Bowers, B. J. (2006). Internet recruitment and e-mail interviews in qualitative studies. Qualitative Health Research, 16(6), 821-835.

Kelner, G. (2004). Transtornos alimentares: Um enfoque psicanalítico. Estudos de Psicanálise, (24), 33-44.

Lisondo, A. B. D. (2004). Na cultura do vazio, patologias do vazio. Revista Brasileira de Psicanálise, 38(2), 335358.

Lutemberg, J. (2003). El vacío mental [Versão eletrônica]. Psicoanálisis: Ayer y Hoy, (1). Recuperado em 28 outubro 2005, de http://www.elpsicoanalisis.org.ar/impnumero1/ vaciomental1-doc.htm

Minayo, M. C. S., \& Sanches, O. (1993). Quantitativoqualitativo: Oposição ou complementaridade? Cadernos de Saúde Pública, 9(3), 239-262.

Miranda, M. R. (2004). O mundo objetal anoréxico e a violência bulímica em meninas adolescentes. Revista Brasileira de Psicanálise, 38(2), 309-334.

Morgan, C. M., Vecchiatti, I. R., \& Negrão, A. B. (2002). Etiologia dos transtornos alimentares: Aspectos biológicos, psicológicos e socioculturais. Revista Brasileira de Psiquiatria, 24(Supl. 3), 18-23.

Mulveen, R., \& Hepworth, J. (2006). An interpretative phenomenological analysis of participation in a proanorexia internet site and its relationship with disordered eating. Journal of Health Psychology, 11(2), 283-296.

Norris, M. L., Boydell, K. M., Pinhas, L., \& Katzman, D. K. (2006). Ana and the internet: A review of pro-anorexia websites. International Journal of Eating Disorders, 39(6), 443-447.

Organização Mundial da Saúde. (1993). Classificação de transtornos mentais e de comportamento da CID-10: Descrições clínicas e diretrizes diagnósticas (D. Caetano, Trad.). Porto Alegre: Artmed. 
Pereira, M. E. C. (1996). Questões preliminares para um debate entre psicanálise e psiquiatria no campo da psicopatologia. In L. F. S. Couto (Org.), Pesquisa em psicanálise (pp. 43-53, Coletâneas ANPEPP, 16). Rio de Janeiro: Associação Nacional de Pesquisa e PósGraduação em Psicologia.

Peres, R. S. (2006). O corpo na psicanálise contemporânea: Sobre as concepções psicossomáticas de Pierre Marty e Joyce McDougall. Psicologia Clínica, 18(1), 165-177.

Peres, R. S., \& Santos, M. A. (2006). Contribuições do desenho da figura humana para a avaliação da imagem corporal na anorexia nervosa. Medicina, 39(3), 361-370.

Selltiz, C., Wrightsman, L. S., \& Cook, S. W. (1987). Dados de observação e de arquivo. In L. H. Kidder (Org.), Métodos de pesquisa nas relações sociais (M. M. H. d'Oliveira \& M. M. del Rey, Trads., pp. 95-120). São Paulo: EPU.

Melina Vianna Fava é psicóloga, especialista em Psicoterapias de Orientação Psicanalítica pela Universidade Federal de São Carlos.

Rodrigo Sanches Peres é Professor Adjunto do Instituto de Psicologia da Universidade Federal de Uberlândia.

Recebido: 04/12/2009

$1^{a}$ revisão: $26 / 11 / 2010$

Aceite final: 30/11/2010 